EXTENDED REPORT

\title{
The impact of the Health Technology Board for Scotland's grading model on referrals to ophthalmology services
}

\author{
S Philip, L M Cowie, J A Olson
}

Br J Ophthalmol 2005;89:891-896. doi: 10.1136/bjo.2004.051334

See end of article for authors' affiliations

.....................

Correspondence to: Dr John Olson, Grampian Diabetes Retinal Screening Programme, Woolmanhill, Aberdeen AB25 1LD, UK

Accepted for publication 11 November 2004
Aim: To ascertain the impact of the Health Technology Board for Scotland's grading model on referrals to ophthalmology services.

Methods: An analysis was performed of the screening outcomes of 5575 consecutive patients, who were screened by the Grampian Diabetic Retinopathy Screening Programme between March and September 2003 according to the recommendations of the Health Technology Board and the Scottish Diabetic Retinopathy Grading Scheme 2003.

Results: 3066 (55\%) were male. The median age was 65 years. $5.4 \%$ were passed on to the level 3 grader and $3.4 \%$ were finally referred to ophthalmology services. $2.3 \%$ required re-screening in 6 months; $85 \%$ were screened without mydriasis; $11.9 \%$ had ungradeable images despite a staged mydriasis protocol. Time to complete grading was 32 days (22-45).

Conclusion: The impact of the Health Technology Board for Scotland's recommendations on referrals to ophthalmology services is modest and should be containable within existing resources.
D iabetic retinopathy is still the commonest cause of blindness in people of a working age in the United Kingdom but there is a long latent period between the onset of diabetic retinopathy and its progression to sight threatening eye disease and blindness. ${ }^{12}$ The Diabetic Retinopathy Study and the Early Treatment Diabetic Retinopathy Study showed that photocoagulation can reduce the risk of severe visual loss by $50 \%$ or more. ${ }^{34}$ Systematic screening for retinopathy among patients with diabetes has been shown to be cost effective. ${ }^{5-7}$ All nations within the United Kingdom are embarking on national screening programmes for diabetic retinopathy. ${ }^{89}$ The most effective and pragmatic model for diabetic retinopathy has yet to be

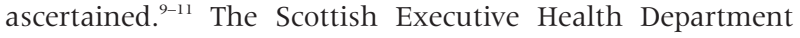
has decided that in Scotland the national diabetic retinopathy screening programme should be implemented according to the recommendations of the Health Technology Board for Scotland. ${ }^{12}$

The Health Technology Board for Scotland's model attempted to optimise "clinical effectiveness and cost effectiveness while respecting patient preference." After applying a rigorous health technology assessment process it recommended a digital photography based screening programme based on single 45 degree disc/macula using a staged mydriasis protocol. ${ }^{12}$ The Health Technology Board for Scotland recommended a three level grading process (fig 1) to enable screening programmes to become quickly established while still protecting patients.

The Scottish Executive Health Department's Diabetic Retinopathy Screening Implementation Group predicted that the impact of this model on referrals to ophthalmology services would be modest based on early experience from Grampian, Lanarkshire and Tayside. ${ }^{8}$ The aim of this study was to assess whether or not this prediction was accurate.

\section{METHODS}

\section{Study population}

The Grampian Diabetes Retinal Screening Programme commenced in April 2002. Grampian's population of 525859 is served by 89 general practices. All patients over the age of
10 years with diabetes mellitus were referred to the retinal screening programme by their general practitioner. Patients could opt out of the screening programme only if they were attending ophthalmology services on a regular basis and the consultant ophthalmologist was willing to continue screening for diabetic retinopathy. In this scenario, the hospital patient administration system was used to confirm the presence of an ophthalmology appointment and whether they attended a specialist medical retina clinic or not. The retinal screening programme had one fixed non-mydriatic 45 degree retinal Canon CR5-45NM camera (Canon Inc, Medical Equipment Business Group, Kanagawa, Japan) based at the Diabetes Centre, Woolmanhill Hospital, Aberdeen, and two mobile Canon CR6-45NM cameras (Canon Inc, Medical Equipment Business Group, Kanagawa, Japan) housed in mobile vans. All cameras were attached to high resolution $(2160 \times 1440$ pixels $)$ Canon D30 digital cameras. At the time of the study there were 15700 patients on the register. Grading and outcome data on all 5575 patients who underwent screening between March 2003 and September 2003 were collated and analysed.

\section{Staffing}

The screening programme employed three level l graders/ retinal photographers, two part-time level 2 graders, and one part-time level 3 grader during the period of the study. Whole time equivalents were 1.0 for level 1 grading, 0.1 for level 2 grading, 0.1 for level 3 grading, and 3.0 for photography. The level 1 graders/retinal photographers had no previous experience in retinal screening before recruitment in January 2003 and underwent a 5 day intensive practical training programme run over 2 weeks. The level 2 graders, all of whom had previous experience in retinal screening, undertook the grading component of the same training programme. The level 3 grader was a consultant in medical ophthalmology.

\section{Screening examination}

Patients had their best visual acuity, with pinhole correction if required, measured by Bailey-Lovie $\log$ MAR charts. ${ }^{13}$ Then, 


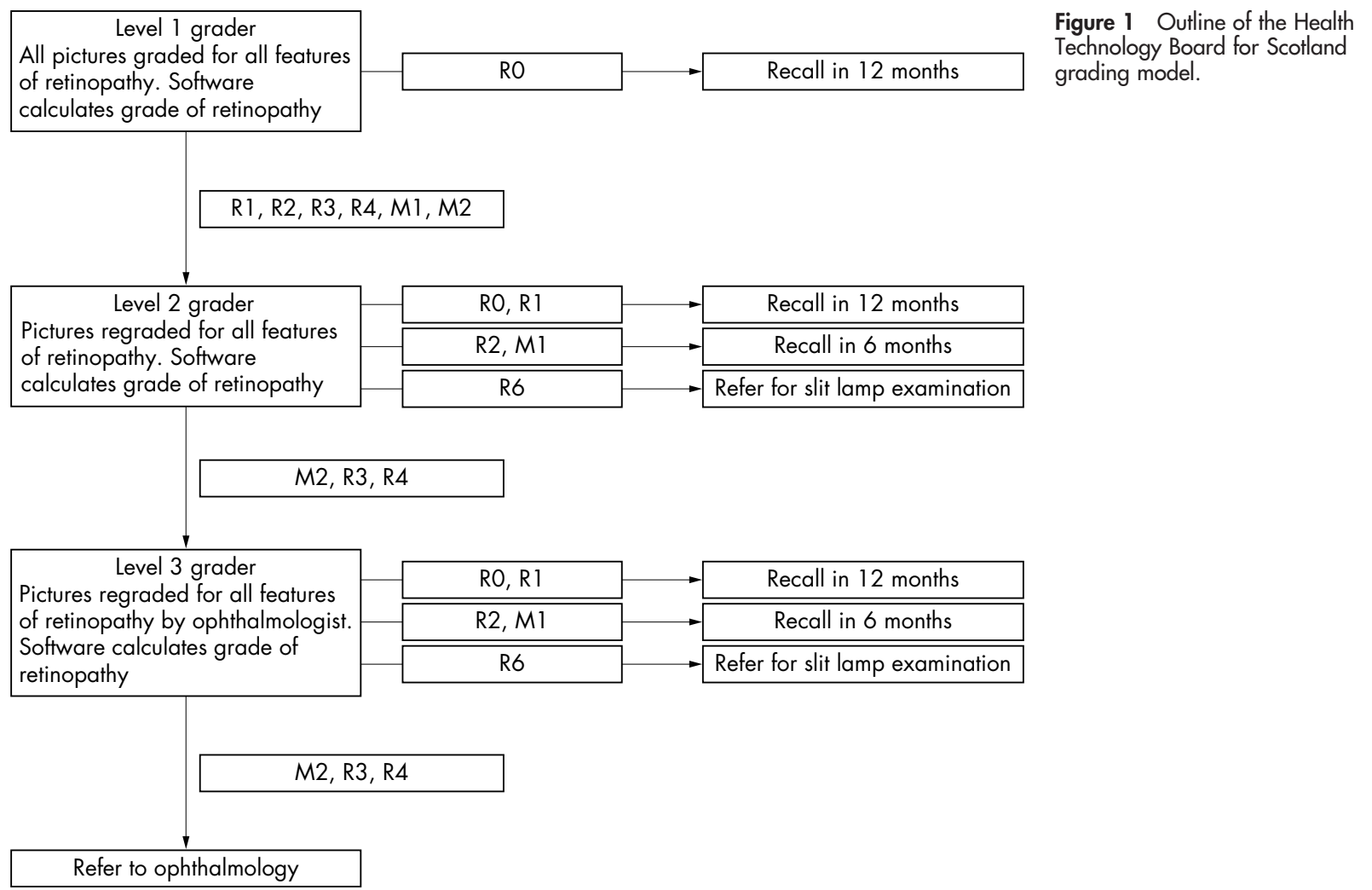

a single $45^{\circ}$ disc/macular field digital image was taken for each eye using a high resolution non-mydriatic digital fundus camera in a darkened room. If the pupils failed physiologically to dilate sufficiently to enable an acceptable image to be obtained, the photograph was repeated at the same visit following mydriasis with tropicamide $1 \%$.
After the grading process, those patients identified as having ungradeable images were invited to attend an additional appointment at the Diabetes Centre, Woolmanhill Hospital, Aberdeen. There, slit lamp examination, following mydriasis with tropicamide $1 \%$, was undertaken by a level 2 grader.

\begin{tabular}{|c|c|c|}
\hline Retinopathy & Description & Outcome \\
\hline $\begin{array}{l}\text { RO } \\
\text { R1 (mild) }\end{array}$ & $\begin{array}{l}\text { No diabetic retinopathy anywhere } \\
\text { Background diabetic retinopathy (BDR), mild } \\
\text { At least one dot haemorrhage or } \\
\text { microaneurysm with or without hard exudates }\end{array}$ & $\begin{array}{l}\text { Re-screen in } 12 \text { months } \\
\text { Re-screen in } 12 \text { months }\end{array}$ \\
\hline R2 (moderate) & $\begin{array}{l}\text { BDR, moderate } \\
\text { Four or more blot haemorrhages (ie, } \geqslant \mathrm{AH}^{*} \\
\text { standard photograph } 2 \mathrm{a} \text { ) in one hemifield } \\
\text { only. (Inferior and superior hemifields are } \\
\text { delineated by a line passing through the } \\
\text { centre of the fovea and the optic disc) }\end{array}$ & $\begin{array}{l}\text { Re-screen in } 6 \text { months (or refer to } \\
\text { ophthalmology if this is not } \\
\text { feasible) }\end{array}$ \\
\hline R3 (severe) & $\begin{array}{l}\text { BDR, severe } \\
\text { Any of the following features } \\
\text { Four or more blot haemorrhages (ie, } \geqslant A H^{*} \\
\text { standard photograph } 2 a \text { ) in both inferior and } \\
\text { superior hemifields } \\
\text { Venous beading (ie, } \geqslant A H^{*} \text { standard } \\
\text { photograph } 6 a \text { ) } \\
\text { IRMA (ie, } \geqslant A H^{*} \text { standard photograph } 8 \mathrm{a} \text { ) }\end{array}$ & Refer to ophthalmology \\
\hline R4 (proliferative) & $\begin{array}{l}\text { Proliferative diabetic retinopathy } \\
\text { PDR } \\
\text { Any of the following features } \\
\text { New vessel } \\
\text { Vitreous haemorrhage }\end{array}$ & Refer to ophthalmology \\
\hline R5 (enucleated) & Enucleated eye & $\begin{array}{l}\text { Re-screen } 12 \text { months } \\
\text { (other eye) }\end{array}$ \\
\hline R6 & Not adequately visualised & Technical failure \\
\hline
\end{tabular}


Table 2 Levels of maculopathy according to Scottish Diabetic Retinopathy Grading Scheme 2003

\begin{tabular}{lll}
\hline Maculopathy & Description & Outcome \\
\hline M1 (observable) & $\begin{array}{l}\text { Lesions within a } \\
\text { radius of }>1 \text { but } \leqslant 2 \text { disc diameters of the } \\
\text { centre of the fovea } \\
\text { Any hard exudates } \\
\text { Lesions within a radius of } \leqslant 1 \text { disc } \\
\text { diameters of the centre of the fovea } \\
\text { Any blot haemorrhages } \\
\text { Any hard exudates }\end{array}$ & $\begin{array}{l}\text { Re-screen in 6 months } \\
\text { (or refer to ophthalmology if this is } \\
\text { not feasible) }\end{array}$ \\
\hline
\end{tabular}

\section{Grading}

Commercial software (Digital Healthcare, UK) was used for image grading and report generation. All graders identified individual features of retinopathy on the images. The retinopathy grade was automatically calculated according to the Scottish Diabetic Retinopathy Grading System 2003. ${ }^{8}$ This was a revised version of the grading scheme recommended by the Health Technology Board for Scotland (tables 1-3).

Level 1 graders graded all images first for image quality and then for retinopathy according to the Scottish Diabetes Retinopathy Grading System 2003 (table 1-3). Images with any retinopathy or those that were of insufficient quality for grading (technical failure) were passed on to a level 2 grader. These images were then re-graded and those deemed to have features of referable retinopathy were passed on to a level 3 grader, a consultant in medical ophthalmology. Both level 2 and level 3 graders could final grade ungradeable images (technical failures). Level 1 and level 2 graders also passed on patients with other significant retinal findings such as retinal vein occlusions and suspicious optic discs. The level 3 grader made the final assessment, confirming or refuting the need for referral to ophthalmology. The level 3 grader also reviewed any images with abnormal features of concern not related to diabetic retinopathy.

Patients with gradeable images stayed within the screening programme unless referred by the level 3 grader to ophthalmology. The final arbiter of referral for patients with ungradeable images was the slit lamp examiner. Patients with coincidental findings of concern were referred to the primary care clinic at the ophthalmology department.

\section{Statistical analysis}

Data were analysed using Statistical Package for Social Sciences (version 11.5.0, SPSS, Chicago, IL, USA). Descriptive data are expressed as mean (SD) or median with 25th and 75 th quartiles. The proportions of patients with different outcomes and different grades of retinopathy were calculated with $95 \%$ confidence intervals. If a patient had assessment by more than one level of grader then the grade assigned by the highest level of grader was taken as the final result.

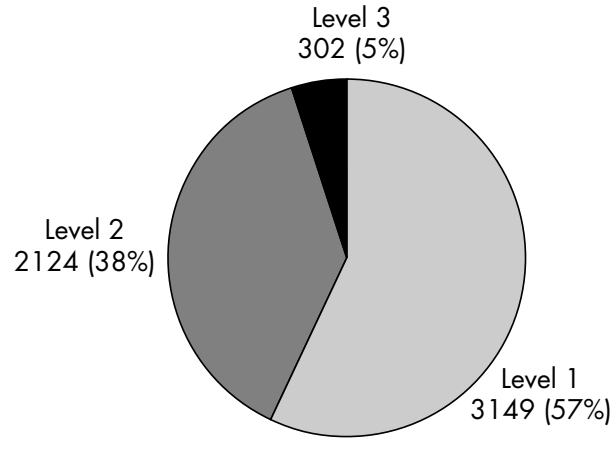

Figure 2 The grading level at which images were assigned the final grade.

\section{RESULTS}

\section{Patient characteristics}

Of the 5575 patients, 3066 (55\%) were male. The median age of patients screened was 65 (54-73) years. Eighty five per cent of the patients were over the age of 45 and $48.2 \%$ over 65 . These demographics were almost identical to those of the Scottish Diabetes Survey 2002. ${ }^{15}$

In all, $4742(85 \%)$ patients had screening without mydriasis. Patients whose images were classed as technical failures were then invited for slit lamp examination were older (mean 74.3 (SD 11.2) years) than those with gradeable images (mean 60.5 (15.5) years, $\mathrm{p}<0.01$ ). Thirteen patients had only one functioning eye $(0.2 \%)$.

\section{Grading process and screening outcomes}

All 5575 patients had their images reviewed by the level 1 grader. Figure 2 shows the number and proportion of images passed on to the level 2 and level 3 graders. Patients assigned their final screening outcome at each grading level are outlined in tables 4 and 5. Fifty seven per cent of patients were assigned their final grade by the level 1 grader. The

\begin{tabular}{|c|c|c|}
\hline Coincidental findings & Description & Outcome \\
\hline $\begin{array}{l}\text { Photocoagulation } \\
\text { Other }\end{array}$ & $\begin{array}{l}\text { Laser photocoagulation scars present } \\
\text { Other non-diabetic lesion present } \\
\text { Pigmented lesion (naevus) } \\
\text { Age related macular degeneration } \\
\text { Drusen maculopathy } \\
\text { Myelinated nerve fibres } \\
\text { Asteroid hyalosis } \\
\text { Retinal vein thrombosis }\end{array}$ & $\begin{array}{l}\text { Not applicable } \\
\text { Refer according to local guidelines }\end{array}$ \\
\hline
\end{tabular}


Table 4 Final screening outcomes at each grading level

\begin{tabular}{lllll}
\hline Screening outcome & Level 1 & Level 2 & Level 3 & Total No (\%) (95\% Cl) \\
\hline Re-screening in 12 months & $3149(56.5 \%)$ & $1368(24.5 \%)$ & $79(1.4 \%)$ & $4596(82.4)(81.5$ to 83.4) \\
Re-screening in 6 months & NA & $107(1.9 \%)$ & $21(0.4 \%)$ & $128(2.3)(1.9$ to 2.7) \\
Referral for slit lamp biomicroscopy & NA & $649(11.6 \%)$ & $12(0.2 \%)$ & $661(11.9)(11.0$ to 12.7) \\
Referral to ophthalmology & NA & NA & $190(3.4 \%)$ & $190(3.4)(3.0$ to 3.9) \\
\hline \multirow{2}{*}{ NA, not applicable as these outcomes could not be assigned at this level. } & \\
\hline
\end{tabular}

median time for complete grading was 32 days (22-45). The main delay in grading appeared to occur at the level 1 stage (median 28 days $(21-40)$ ).

The level 1 grader passed on images of 2426 (43.5\%) patients to the level 2 grader. Only 302 (5.4\%) were subsequently passed on to the level 3 grader, a consultant in medical ophthalmology, for final assessment. At final assessment, the level 3 grader agreed that 190 patients should be referred to ophthalmology services including five patients who had significant non-diabetes pathology (retinal vein occlusions, two; glaucoma, two; large naevus, one). However, for 112 patients the level 3 grader disagreed, recommending that 21 should be re-screened in 6 months, 33 should be rescreened in 12 months, 46 did not have significant nondiabetes pathology, and 12 were ungradeable requiring slit lamp examination. Only 331 (5.9\%) patients passed on by the level 1 grader as having any retinopathy were finally downgraded by a higher level grader as having no retinopathy

After final grading, 3485 patients $(62.5 \%)$ had no retinopathy, while 18 patients $(0.3 \%)$ had proliferative retinopathy (table 5). The most frequent cause for referral to ophthalmology services was referable maculopathy (131 patients, $2.3 \%)$.

\section{DISCUSSION}

This study provides outcome data on the impact of the Health Technology Board for Scotland's grading model on referrals to ophthalmology from a primary care based diabetic retinopathy screening programme using digital photography that meets the recommended resolution agreed by both the Health Technology Board for Scotland and the National Screening Committee for England. ${ }^{9}{ }^{12}$

The Health Technology Board for Scotland's grading model appears to be effective in triaging patients needing review by the third level grader. Only $302(5.4 \%)$ patients' images needed review by the third level grader and, of those, 190 $(3.4 \%)$ were finally referred to ophthalmology services. Only $10 \%$ of the images passed to the level 3 grader were downgraded for review in 12 months. Most errors were caused by the misclassification of referable maculopathy such as misjudging the position of blot haemorrhages or exudates, incorrectly classifying drusen as exudates or mistaking dot haemorrhages for blots haemorrhages.
A major difference between the recommendations for Scotland and those for England is that in Scotland, patients with ungradeable images requiring slit lamp examination are to be contained within the screening programme, whereas in England they are to be referred to ophthalmology services. In our study 661 patients $(11.9 \%)$ required re-invitation for examination by slit lamp biomicroscopy. The reported rates for technical failures in other studies vary from 3.7\% to $19.7 \% .{ }^{16-21}$ In the study by Scanlon et al, the technical failure rate for mydriatic photography was reported as $3.7 \%$; however, a further $15.5 \%$ of patients had only "partially assessable images." ${ }^{18}$ Comparisons of technical failure figures are difficult because of a lack of standard image quality assessment protocols; however, our high technical failure rate might be explained by the presence of two new photographers during the study period who were still in their learning phase. Patients were also in their first systematic screening cycle when those who had undiagnosed cataract or other permanent media opacities, might first be encountered. In the second screening cycle these patients would be offered slit lamp examination, if cataract surgery was inappropriate, rather than digital photography, which should lead to a lower photographic technical failure rate. Furthermore, although high resolution cameras, as recommended by the Health Technology Board for Scotland, have diagnostic advantages, their use of a higher intensity flash compared to that used by lower resolution cameras may result in increased reflections from media opacities increasing the technical failure rate. In addition, the relative quality of the good photographs obtained by high resolution cameras is also better, thus the threshold for rejecting photographs may be higher. Though our technical failure rates are higher than others have documented we think they are realistic for newly established screening programmes. Regardless, provision must be made for those patients with ungradeable images. In Scotland it has been recommended that this resource be provided within the screening programme, an alternative would be to set up a dedicated clinic within ophthalmology. Which is more effective has yet to be determined.

Another difference between the Health Technology Board for Scotland and the National Screening Committee recommendations for England is the presence of a 6 monthly rescreening interval for borderline patients (table 4). ${ }^{9}$ The Health Technology Board for Scotland recommended that

Table 5 Overall grades of retinopathy assigned for patients screened

\begin{tabular}{ll}
\hline Overall level of retinopathy or maculopathy & Number of patients (\%) (95\% Cl) \\
\hline R0: No diabetic retinopathy & $3485(62.5)(61.2$ to 63.7$)$ \\
R1: Mild diabetic retinopathy & $1116(20.0)(18.9$ to 21.0$)$ \\
R2: Moderate diabetic retinopathy & $17(0.3)(0.2$ to 0.5$)$ \\
M1: Observable maculopathy & $111(2)(1.7$ to 2.4$)$ \\
M2: Referable maculopathy & $131(2.3)(2.0$ to 2.8$)$ \\
R3: Severe diabetic retinopathy & $36(0.6)(0.5$ to 0.9$)$ \\
R4: Proliferative diabetic retinopathy & $18(0.3)(0.2$ to 0.5$)$ \\
R6: Image is of a quality inadequate for grading & $661(11.9)(11.0$ to 12.7$)$
\end{tabular}


patients with "moderate background retinopathy" or "observable maculopathy" could be re-screened at 6 months or referred to ophthalmology services if the screening programme lacked the capacity to contain them within the programme. ${ }^{12}$ In our study 128 patients $(2.3 \%$ (1.9-2.7)) fell into these borderline categories and were re-screened at 6 months thus reducing the impact of the screening programme on ophthalmology services.

There are also differences with respect to classification of diabetic maculopathy. The National Screening Committee for England recommends that patients with a dot or blot haemorrhage at the macula are referred if they have a visual acuity of worse than or equal to 6/12. Using the National Screening Committee for England's criteria this would have resulted in an additional $159(2.8 \%)$ referrals.

The number of patients in our study who needed referral to ophthalmology services was lower than others have suggested and has not yet led to the requirement for any additional resources within ophthalmology services. Using a low resolution digital mydriatic photographic screening method, Scanlon et al had a $12.2 \%$ referral rate for patients not already under the care of an ophthalmologist. ${ }^{18}$ However, this figure included patients with technical failures in either eye as these patients were not contained within the screening programme. In Liverpool between 1991 and 1999, using colour slide mydriatic photography, a "high resolution" technique, a referral rate of $7.1 \%$ was obtained. ${ }^{22}$ In Newcastle using combined mydriatic Polaroid photography and mydriatic direct ophthalmoscopy a referral rate of $4.5 \%$ was documented..$^{23}$ Our lower referral rate of $3.4 \%$ may reflect the effectiveness of previous retinal screening performed at hospital diabetes clinics in Grampian or, alternatively, may reflect different population demographics compared to other studied populations. The population of Grampian is relatively affluent and predominantly white. ${ }^{24}{ }^{25}$ Other ethnic groups are known to be at a higher risk of developing diabetic retinopathy and to have a higher rate of cataract formation. ${ }^{26-28}$ It is possible that higher rates of untreated cataract formation will be found in a less affluent population. ${ }^{29}$

If all patients with ungradeable pictures are to be referred to ophthalmology, and in addition there is not a 6 month review group, then the National Screening Committee for England's prediction of an $8 \%$ initial referral rate to ophthalmology services seems low. Furthermore, as the National Screening Committee for England recommends a two field photographic schedule then it is likely that the technical failure rate will be higher if both photographs need to meet image quality standards.

Ophthalmology time will be required to train retinal screeners to grade before any screening programme can commence. The exact amount and level of training needed is still being debated throughout the four nations. Our experience, based on internal quality assurance by the level 3 grader, suggests that newly appointed level 1 graders with no previous experience of retinal screening can be quickly trained to accurately identify images with no features of retinopathy.

Finally, grading for quality assurance may place a significant burden on ophthalmology services. National Health Service Quality Improvement Scotland has published diabetic retinopathy screening standards for Scotland that state that "the images from a minimum of 500 randomly selected patients (or all images graded if less than 500 patients) per grader per annum not otherwise referred to a third level grader are reviewed by a third level grader." ${ }^{\prime 30}$ As the Grampian Diabetes Retinal Screening Programme has five graders, this equates to 2500 patients (1250 over 6 months) per annum. The National Screening Committee for England recommends that $10 \%$ of the normal patients
(348 patients in our study) should be regraded by a second level grader rather than an ophthalmologist. ${ }^{31}$ In addition, it recommends that ideally each grader should read a minimum of 1500 and maximum of 4000 patients per annum. National Health Service Quality Improvement Scotland took the view that until diabetic retinopathy screening programmes had become established and that there were proved training programmes for retinal screeners then this quality assurance would have to be performed by medical retina specialists. In time, however, it is hoped that this burden could be shared by other healthcare professionals.

In conclusion, the Health Technology Board for Scotland's three level grading model appears to be effective in both triaging patients needing review by the level 3 grader and in minimising the numbers of unnecessary referrals to ophthalmology services. Thus, the impact of the Health Technology Board for Scotland's recommendations should be modest, enabling referrals to be contained within existing ophthalmology resources in Scotland.

\section{ACKNOWLEDGEMENTS}

The authors gratefully acknowledge the invaluable assistance of the retinal screening nurses and the administrative staff of the Grampian Diabetes Retinal Screening Programme.

\section{Authors' affiliations}

S Philip, L M Cowie, J A Olson, Grampian Diabetes Retinal Screening Programme, Woolmanhill, Aberdeen AB25 ILD, UK

\section{REFERENCES}

1 Bamashmus MA, Matthaga B, Dutton GN. Causes of blindness and visual impairment in the west of Scotland. Eye 2004;18:257-61.

2 Evans J, Rooney C, Ashwood F, et al. Blindness and partial sight in England and Wales: April 1990-March 1991. Health Trends 1996;28:5-12.

3 Early Treatment Diabetic Retinopathy Study Research Group. Photocoagulation for diabetic macular edema. Early Treatment Diabetic Retinopathy Study report number 1. Arch Ophthalmol 1985; 103:1796-806.

4 The Diabetic Retinopathy Study Research Group. Photocoagulation treatment of proliferative diabetic retinopathy. Clinical application of Diabetic Retinopathy Study (DRS) findings, DRS Report Number 8. Ophthalmology $1981 ; 88: 583-600$.

5 Foulds WS, McCuish A, Barrie T, et al. Diabetic retinopathy in the west of Scotland: its detection and prevalence, and the cost-effectiveness of a proposed screening programme. Health Bull (Edinb) 1983;41:318-26.

6 Sculpher MJ, Buxton MJ, Ferguson BA, et al. Screening for diabetic retinopathy: a relative cost-effectiveness analysis of alternative modalities and strategies. Health Econ 1992;1:39-51.

7 James M, Turner DA, Broadbent DM, et al. Cost effectiveness analysis of screening for sight threatening diabetic eye disease. BMJ 2000;320:1627-31.

8 Diabetic Retinopathy Screening Implementation Group. Diabetic retinopathy screening services in scotland: recommendations for implementation. Edinburgh: Scottish Executive, 2003:69-70.

9 Harding S, Greenwood R, Aldington S, et al. Grading and disease management in national screening for diabetic retinopathy in England and Wales. Diabet Med 2003;20:965-971.

10 Lau HC, Voo YO, Yeo KT, et al. Mass screening for diabetic retinopathy-a report on diabetic retinal screening in primary care clinics in Singapore. Singapore Med J 1995;36:510-13

11 Peters AL, Davidson MB, Ziel FH. Cost-effective screening for diabetic retinopathy using a nonmydriatic retinal camera in a prepaid health-care setting. Diabetes Care 1993;16:1193-5.

12 Facey K, Cummins E, Macpherson K, et al. Organisation of services for diabetic retinopathy screening, Health Technology Assessment Report 1. Glasgow: Health Technology Board for Scotland, 2002.

13 Lovie-Kitchin JE. Validity and reliability of visual acuity measurements. Ophthalmic Physiol Opt 1988;8:363-70.

14 Davis MD, Norton EWD, Myers FL. The Airlie classification of diabetic retinopathy. In: Goldberg MF, Fine SL, eds. Symposium on the treatment of diabetic retinopathy. US Dept of Health, Education and Welfare, 1968:7-37.

15 Scottish Diabetes Survey Monitoring Group. Scottish Diabetes Survey 2002. Edinburgh: Scottish Executive Health Department, 2002:18-19.

16 Olson JA, Strachan FM, Hipwell JH, et al. A comparative evaluation of digital imaging, retinal photography and optometrist examination in screening for diabetic retinopathy. Diabet Med 2003;20:528-34. 
17 Massin P, Erginay A, Ben Mehidi A, et al. Evaluation of a new non-mydriatic digital camera for detection of diabetic retinopathy. Diabet Med 2003;20:635-41

18 Scanlon PH, Malhotra R, Thomas G, et al. The effectiveness of screening for diabetic retinopathy by digital imaging photography and technician ophthalmoscopy. Diabet Med 2003;20:467-74.

19 Herbert HM, Jordan K, Flanagan DW. Is screening with digital imaging using one retinal view adequate? Eye 2003;17:497-500

20 Boucher MC, Gresset JA, Angioi K, et al. Effectiveness and safety of screening for diabetic retinopathy with two nonmydriatic digital images compared with the seven standard stereoscopic photographic fields. Can J Ophthalmol 2003;38:557-68

21 Agrawal A, McKibbin MA. Technical failure in photographic screening for diabetic retinopathy. Diabet Med 2003:20:777.

22 Younis N, Broadbent DM, Vora JR, et al. Prevalence of diabetic eye disease in patients entering a systematic primary care-based eye screening programme. Diabet Med 2002; 19:1014-21.

23 Pandit RJ, Taylor R. Quality assurance in screening for sight-threatening diabetic retinopathy. Diabet Med 2002;19:285-91.

24 Social Disadvantage Research Centre. Scottish indices of deprivation index 2003. Edinburgh: Scottish Executive, 2003:21-28.
25 Office of Chief Statistician. Analysis of ethnicity in the 2001 census. Edinburgh: Scottish Executive, 2004:26.

26 Pardhan S, Gilchrist J, Mahomed I. Impact of age and duration on sightthreatening retinopathy in South Asians and Caucasians attending a diabetic clinic. Eye 2004; 18:233-40.

27 Mather HM, Chaturvedi N, Kehely AM. Comparison of prevalence and risk factors for microalbuminuria in South Asians and Europeans with type 2 diabetes mellitus. Diabet Med 1998;15:672-7.

28 Das BN, Thompson JR, Patel R, et al. The prevalence of eye disease in Leicester: a comparison of adults of Asian and European descent. J R Soc Med 1994;87:219-22

29 Klein BE, Klein R, Lee KE, et al. Socioeconomic and lifestyle factors and the 10year incidence of age-related cataracts. Am J Ophthalmol 2003;136:506-12.

30 NHS Quality Improvement Scotland. Diabetic retinopathy screening clinical standards-March 2004. Edinburgh: Scottish Executive Health Department, 2004:31.

31 UK National Screening Committee. Essential elements in developing a diabetic retinopathy screening programme. 2004:43

(www.nscretinopathy.org.uk/ resources/FinalWorkbook2doc, accessed 27 May 2004.). 